\title{
Wireless Power Supply via Coupled Magnetic Resonance for on-line Monitoring Wireless Sensor of High-voltage Electrical Equipment
}

\author{
Xingkui, Mao; Qisheng, Huang; Yudi, Xiao; Shifa, Lan; Zhang, Zhe; Andersen, Michael A. E.
}

Published in:

Proceedings of 42nd Annual Conference of IEEE Industrial Electronics Society

Link to article, DOI:

10.1109/IECON.2016.7793110

Publication date:

2016

Document Version

Peer reviewed version

Link back to DTU Orbit

Citation (APA):

Xingkui, M., Qisheng, H., Yudi, X., Shifa, L., Zhang, Z., \& Andersen, M. A. E. (2016). Wireless Power Supply via Coupled Magnetic Resonance for on-line Monitoring Wireless Sensor of High-voltage Electrical Equipment. In Proceedings of 42nd Annual Conference of IEEE Industrial Electronics Society (pp. 4582-4587). IEEE. https://doi.org/10.1109/IECON.2016.7793110

\section{General rights}

Copyright and moral rights for the publications made accessible in the public portal are retained by the authors and/or other copyright owners and it is a condition of accessing publications that users recognise and abide by the legal requirements associated with these rights.

- Users may download and print one copy of any publication from the public portal for the purpose of private study or research.

- You may not further distribute the material or use it for any profit-making activity or commercial gain

- You may freely distribute the URL identifying the publication in the public portal 


\section{Wireless Power Supply via Coupled Magnetic Resonance for on-line Monitoring Wireless Sensor of High-voltage Electrical Equipment}

\begin{abstract}
On-line monitoring of high-voltage electrical equipment (HV-EE) aiming to detect faults effectively has become crucial to avoid serious accidents. Moreover, highly reliable power supplies are the key component for the wireless sensors equipped in such on-line monitoring systems. Therefore, in this paper, the wireless power supply via coupled magnetic resonance (MR-WPS) is proposed for powering the wireless sensor and the associated wireless sensor solution is also proposed. The key specifications of the MR-WPS working in switchgear cabinet with a harsh operation environment are analyzed and determined. Design of these key parameters of the coupled magnetic resonant unit (CMRU) in MR-WPS is provided as well as the method of optimizing the resonant windings is given. Finally, a prototype is built and tested. The experimental results are presented in order to show that sufficient and reliable power is able to be delivered to the wireless sensor through the designed MR-WPS, and therefore the theoretical analysis and design is verified.
\end{abstract}

Keywords: Wireless power supply; Coupled magnetic resonance; High-voltage electrical equipment; Wireless sensor

\section{Introduction}

On-line monitoring aims to detect early signs of failure in electrical equipment, and then maintenance was carried out to eliminate hidden dangers to avoid fatal accidents in time. Compared to using optical fiber with good insulation to transmit the monitoring data under high-voltage application, wireless sensor transmitting data by electromagnetic wave (wireless sensor ) has such advantages as no wire layout, high insulation and flexibility etc. Wireless sensor has been one of effective ways for on-line monitoring in HV-EE characterized of high voltage, strong magnetic field, compact mechanical structure and electrical insulation requirements.

Operation of wireless sensor needs to be powered. Because of high-voltage and electrical insulation, the wireless sensor cannot get operation power from neither bus bar of HV-EE nor utility grid directly. Therefore, operation power for the wireless sensor has been one of the key technologies for its wider applications and further developments ${ }^{[1-3]}$. Now, the main powering ways of the wireless sensor includes lithium battery, and current transformer (CT). Lithium battery powering suffers from shortcomings as limited battery capacity, poor high-temperature performance, and especially power outage of HV-EE for renewing the batteries. CT powering is a method to pick up energy from the bus bar of HV-EE via winding with magnetic core and the winding mounted to pass through the bus bar However, powering capability of CT highly depends on the bus bar current. The picking energy is not enough for operation power under small bus bar current, while the wireless sensor would be interfered under overcurrent and short current caused by failure of power system, even was damaged. In particularly, there are very large amount of existed HV-EEs, and these HV-EE or their key components should be reconstructed greatly when mounting the picking energy CT. This reconstruction is high cost to be impossible.

Power can be transmitted without electrical contact through of wireless power transmitting technology, and now it is usually used in consumer electronics and electric vehicles etc. ${ }^{[4-6]}$. Wireless power transmission via coupled magnetic resonance is capable of transferring relatively high power under long distance [7-11]; this will satisfy electrical insulation required by HV-EE. The MR-WPS for the on-monitoring wireless sensor of HV-EE is proposed in this paper. And this MR-WPS not only provides enough and stable operations power for the wireless sensor, but also meet the electrical insulation standard of HV-EE. This paper is structured as follows. After this Introduction, Section II presents the proposed MR-WPS key specifications and configurations. Section III describes the CMRU modeling and windings design. Section IV presents a prototype and its running in $6.3 \mathrm{kV}$ switchgear cabinets. Finally the conclusion is given.

\section{Wireless sensor powered by MR-WPS}

High-voltage switchgear cabinet is a typical HV-EE. The cabinet covered by metal shell has compact mechanical structure, and also contains lots of metal components inside. This structure will take harsh working environment for the MR-WPS via high-frequency magnetic field to transmit power in air. By deep analysis of electrical insulation standard, 
the cabinet internal mechanical structure, and operation power of the wireless sensor, key specifications of the MR-WPS was introduced as listed in Table 1,

Table 1. Key specifications of the MR-WPS in switch gear cabinet

\begin{tabular}{|l|l|}
\hline Input AC voltage & $176-265 \mathrm{~V} / 50 \mathrm{~Hz}$ \\
\hline Output DC & $\begin{array}{l}3.3 \mathrm{~V} / 0.5 \mathrm{~W} \\
\text { (power consumption of the wireless sensor) }\end{array}$ \\
\hline Transmission distance & $13-18 \mathrm{~cm}$ \\
\hline Emitting winding & Radius $40 \mathrm{~mm}$, and height $5 \mathrm{~mm}$ \\
\hline Receiving winding & Radius $25 \mathrm{~mm}$, and height $5 \mathrm{~mm}$ \\
\hline
\end{tabular}

Notes: the $220 \mathrm{~V}$ AC power for protection and lighting etc. inside the cabinet is used as input of the MR-WPS; Insulation distance of phase to ground, and phase to phase is $10-18 \mathrm{~cm}$ in China National Standard for HV-EE with 3-20 kV indoor; Winding size and installation should be met or not break the insulation standard.

The system diagram of the proposed wireless sensor for HV-EE powered by MR-WPS is proposed in Fig.1. According to their functions, the system can be divided into two parts i.e. MR-WPS (block with red font) and the wireless sensor (block with blue font). It should be noted that the on-monitoring data is transmitted in the wireless sensor, while the power is transmitted in the MR-WPS. The wireless sensor, which consists of sensor, micro controller, wireless transmitting data module (here Digi's XBEE is used), and personal computer, is in charge of monitoring status of HV-EE and transmitting the monitoring data to $\mathrm{PC}$ or other data processing center. It can be seen that this part has the same structure with the previous wireless sensor for HV-EE except for its powering. The MR-WPS can be further divided into parts of emitting side and receiving side. The power circuit is given in Fig.2. In the emitting side, the power circuit is constructed with Flyback converter, which converting utility grid AC voltage into regulated DC voltage, and class $\mathrm{E}$ power amplifier which inverting $\mathrm{DC}$ voltage fed by Flyback converter into $\mathrm{AC}$ current for exciting the coupled magnetic resonance unit. By the magnetic coupled magnetic resonance, the high-frequency AC power is transmitted from emitting side to receiving side with the help of corresponding compensation network. Then the DC voltage rectified by diodes D1-D4 is regulated by Buck converter to supply the wireless sensor. It is noted that the wireless feedback control of MR-WPS is embedded in the wireless sensor to share its micro-controller and Zigbee module. The micro-controller also senses output voltage of the MR-WPS, and then it is feedback to the emitting side via the Zigbee module.

In the wireless sensor powered by MR-WPS, the "receiving side of MR-WPS" and the wireless sensor is installed on high-voltage side of HV-EE, and the "emitting side" and personal computer must be installed to keep outside electrical insulation distance, while keep within effective distance for wireless power and data transmission. Although the data transmission distance is much larger than electrical insulation distance in open space (the effective data transmission distance of Digi's XBEE is up to $100 \mathrm{~m}$ ). However, this distance would be greatly attenuated because of the cabinet is covered by metal shell. But in the previous wireless sensor, the Zigbee module will be usually set under low transmitting power mode to make the batteries to last longer time Moreover, the network of the wireless sensor (the wireless sensor will be networked with protocols, such as Zigbee, to monitor a great deal of nodes of HV-EE) will be set into sleep mode under no transmitting data, and would be activated when starting data transmission. This working mode will lead to networking failure when activating. In contrast with lithium battery powering or CT powering, MR-WPS powering, which get power from utility grid on emitting side, could provide sufficient and stable power, resulting in not only the working time of the wireless sensor no longer limited by its operation power, but also longer data transmission distance and more higher reliability of the network without setting low transmitting power mode and sleep mode.

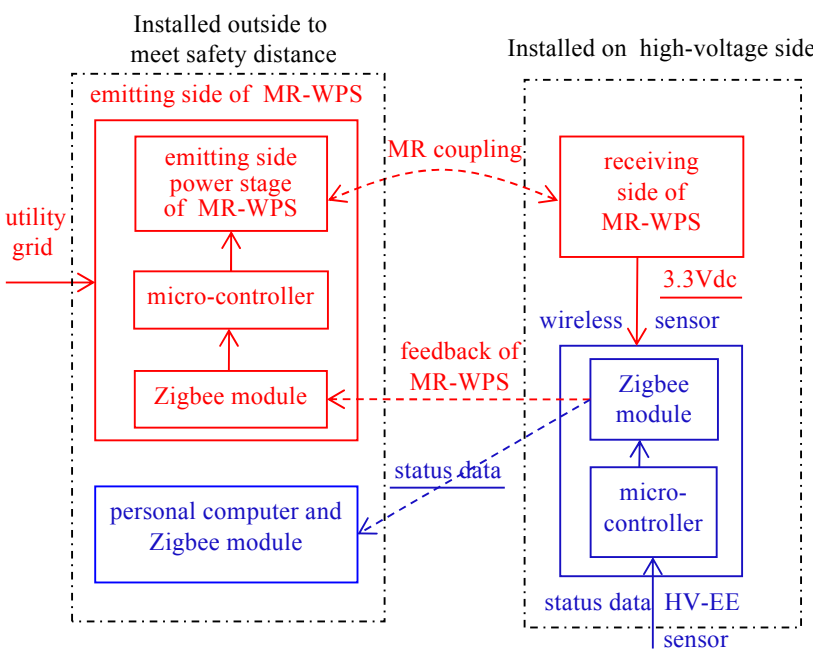

Fig.1 System diagram of the wireless sensor for HV-EE powered by MR-WPS

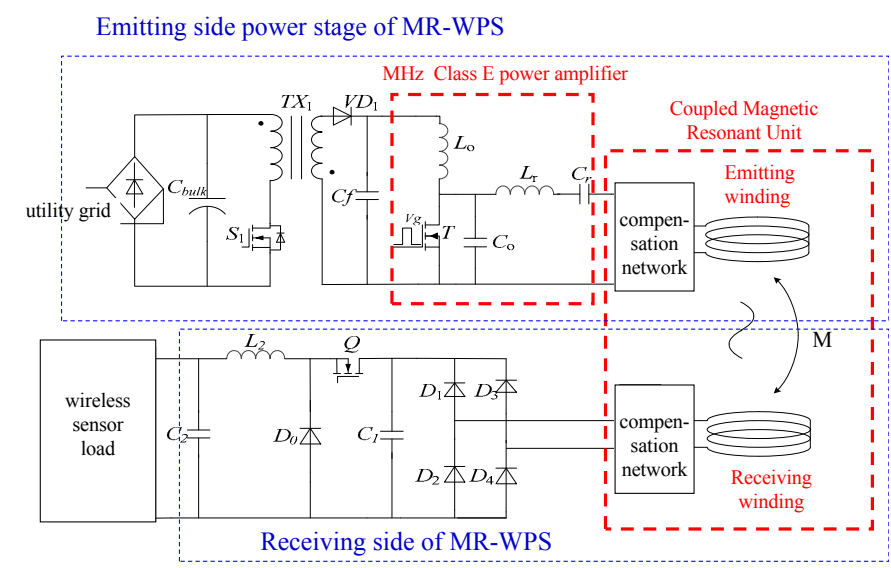

Fig.2 Power stage of MR-WPS

\section{Modeling and design of the CMRU}

\subsection{Modeling of the CMRU}

As a key part of the MR-WPS, the CMRU including windings and the corresponding compensation network has great effect on its transmission distance, power level and efficiency etc. The coupled magnetic structures can be mainly classified into two types: two winding structure and four 
winding structure ${ }^{[7],[8]}$. The four winding structure derived from the two winding structure by introducing a impedance matching winding into source and load respectively to eliminate the influences on resonant windings (emitting winding and receiving winding) resulted from source and load variation. As a result, a better transmission performance can be obtained. Therefore, the four winding structure is selected to be as the coupled magnetic unit for MR-WPS.

The four winding structure with series-connecting compensation capacitance is shown in Fig.3. The Fig.3 (b) is the corresponding mutual inductance model. In the model, $I_{s}$ and $R_{s}$ is the high-frequency exciting source and its internal resistance; $L_{1}, L_{2}, L_{3}$, and $L_{4}$ represent self-inductance of each winding respectively; $C_{1}, C_{2}, C_{3}$, and $C_{4}$ represent series-connecting compensation capacitance for each winding respectively; $R_{1}, R_{2}, R_{3}$, and $R_{4}$ represent the resistance of each winding under high-frequency exciting respectively; $M_{12}, M_{23}$, and $M_{34}$ represents mutual inductance between the two adjacent windings; $R_{L}$ is the load resistance; $Z_{i}=R_{i}+j X_{i}$ represents the input impedance of the coupled magnetic unit; $Z{ }_{i}=R_{i}{ }_{i}+j X_{i}^{\prime}$ represents impedance from emitting winding port; $Z_{o}=R_{o}+j X_{o}$ represents equivalent load impedance from load compensation winding port. The efficiency of the MR-WPS with four winding structure is divided into three parts $\eta_{12}, \eta_{23}$, and $\eta_{34}$ as shown in Fig.3 (b).

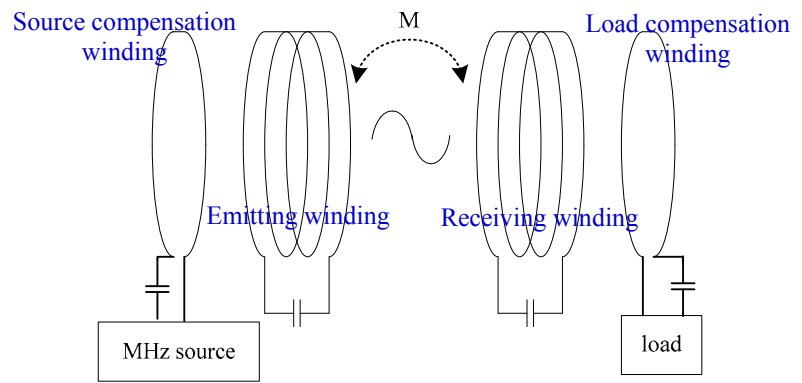

(a) Four winding structure with series -connecting compensation capacitance

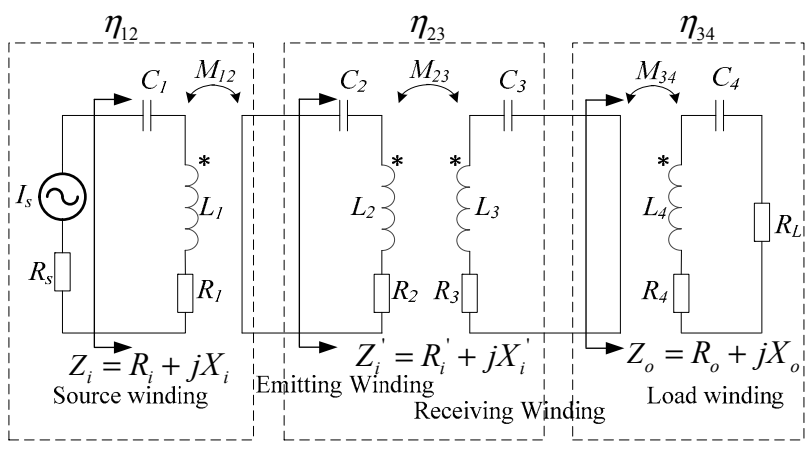

(b) Mutual inductance model

Fig3. Four winding structure with series-connecting compensation capacitance and its mutual inductance model

In the design, both source compensation winding and load compensation winding are constructed with single turn to obtain small winding resistance $R_{l}$ and $R_{4}$. Impedance $Z_{i}, Z^{\prime}{ }_{i}$ and $Z_{o}$ is purely resistive when each winding operates resonantly by design of exciting frequency and compensation capacitances, thus $R_{i}, R_{i}^{\prime}$, and $R_{o}$ can be written as follows,

$$
\left\{\begin{array}{l}
R_{i}=R_{1}+\frac{\left(\omega_{0} M_{12}\right)^{2}}{R_{i}^{\prime}} \approx \frac{\left(\omega_{0} M_{12}\right)^{2}}{R_{i}^{\prime}} \\
R_{i}^{\prime}=R_{2}+\frac{\left(\omega_{0} M_{23}\right)^{2}}{R_{3}+R_{o}} \\
R_{o}=\frac{\left(\omega_{0} M_{34}\right)^{2}}{R_{4}+R_{L}} \approx \frac{\left(\omega_{0} M_{34}\right)^{2}}{R_{L}}
\end{array}\right.
$$

$\omega_{0}$ represents resonant frequency in the equation.

The total efficiency $\eta$ of the CMRU can be expressed as a product of transmission efficiency between the two adjacent windings i.e. $\eta=\eta_{12} \eta_{23} \eta_{34}$, where

$$
\begin{aligned}
& \eta_{12} \approx \frac{R_{i}}{R_{s}+R_{i}}, \quad \eta_{34} \approx 1 \\
& \eta_{23}=\frac{\left(\omega_{o} M_{23}\right)^{2} R_{o}}{\left(R_{3}+R_{o}\right)\left(R_{2}\left(R_{3}+R_{o}\right)+\left(\omega_{o} M_{23}\right)^{2}\right)}
\end{aligned}
$$

When the equivalent load is equal to as follows,

$$
R_{o_{-} \text {opt }}=\sqrt{\frac{R_{3}\left(\omega_{0} M_{23}\right)^{2}}{R_{2}}+R_{3}^{2}}
$$

$\eta_{23}$ will be maximized as,

$$
\eta_{23 \_ \text {max }}=\frac{k_{Q}{ }^{2}}{k_{Q}{ }^{2}+2 \sqrt{k_{Q}{ }^{2}+1}+2}
$$

Where $k_{Q}=k_{23} \sqrt{Q_{2} Q_{3}} \quad, \quad k_{23}=M_{23} / \sqrt{L_{2} L_{3}}$ represents coupling coefficient between the emitting winding and receiving winding; $Q_{2}=\omega_{0} L_{2} / R_{2}$ and $Q_{3}=\omega_{0} L_{3} / R_{3}$ represent quality factor of the emitting and receiving windings respectively. It can be seen that, the maximum efficiency $\eta_{23}$ max only depends on $k_{Q}$ determined by the intrinsic parameters $k_{23}, Q_{2}$, and $Q_{3}$ of the windings.

As shown in Equation (1), the input resistance $R_{i}$ and equivalent load resistance $R_{o}$ can be modified by regulating $M_{12}$ and $M_{34}$ respectively. Efficiency $\eta_{12}$ could approach to 1 when regulating $R_{i}$ much larger than $R_{s}$ by increasing $M_{12}$. Efficiency $\eta_{23}$ could be maximized when $R_{o}=R_{O_{-} o p t}$ by regulating $M_{34}$.

The curve of Fig.4 can be plotted from Equation (5). It can be seen that, $\eta_{23 \_} \max$ will decreases with decreasing of $k_{Q}$, and drops rapidly on the left side of point a. Therefore, $k_{Q}$ should be designed on the right side of point a if there is no limitations in the design $k_{Q}$ or the windings geometry sizes. And if the $k_{Q}$ can be designed on the left side of point a because of restrictions, it should be designed as large as 
possible for getting high efficiency of power transmission or high capability of power transmission. $Q_{2}$ and $Q_{3}$ should be increased because of relatively small $k_{23}$ existing under long transmission distance.

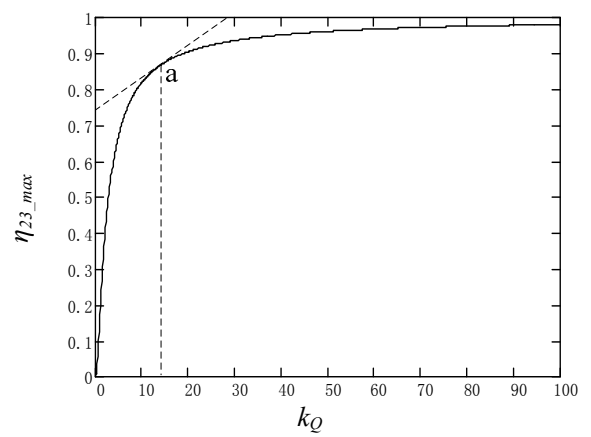

Fig4. Maximum efficiency $\eta_{23 \_ \text {max }}$ vs. $k_{Q}$

\subsection{Design and optimization of the coupled windings}

The winding size of the CMRU is strictly limited because of electrical insulation requirements of HV-EE and lots of metal components inside. Therefore, it is necessary to design and optimize winding structure for better transmission performances in a strictly limited size. As expressed in "section 3.1", the main targets in design and optimization of the windings are coupling coefficient $k$ and quality factor $Q_{2}$, $Q_{3}$. The $k$ is designed to improve slightly under the fixed winding size and transmission distance. So in the following design and optimization, the main target is to improve $Q_{2}, Q_{3}$ under setting the allowable maximum size for the windings. The winding quality factor is determined by its inductance and resistance, and they are greatly affected by eddy current under high-frequency operation. In general, the calculation inductance of spiral winding inductance has high engineering precision, but the precision is not high in winding resistance calculation. Therefore, design and optimization of windings can be implemented to estimate the turn numbers of air-core winding by the analytical model of inductance firstly, then using high-frequency eddy current simulator of finite-element software ANSOFT. The structure diagram of spiral air-core winding is shown in Fig.5, where $R$ represents the outer radius of winding, $L_{a y}$ represents the number of winding layers, $N$ represents the number of turns on each layer, $r$ represents the radius of winding conductor, $s$ represents the distance between two adjacent layers, $h$ represents the distance between centers of the two adjacent winding on the same layer. A single layer solenoid coil could be obtained by setting $L_{a y}=1$.

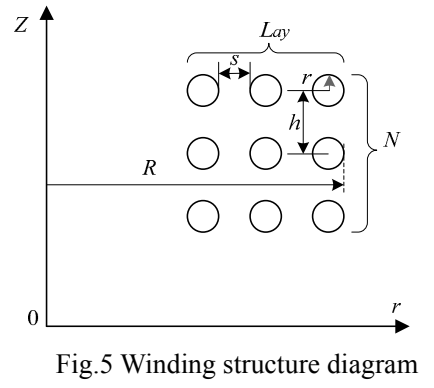

The power transmission capability and efficiency can be effectively improved by increasing operating frequency in
MR-WPS. However, the absorptions of human tissue to the time-varying magnetic field would be improved if the operating frequency exceeds $4 \mathrm{MHz}{ }^{[12]}$. Therefore, the operating frequency is set to $4 \mathrm{MHz}$ for the CMRU or the MR-WPS. Furthermore, the resonant capacitance or compensation capacitance will decrease when increasing the winding inductance under a fixed resonant frequency. And the consistency of operation frequency or resonant frequency will become worse when the compensation capacitance approximates to parasitic capacitance of the winding. Here the resonant capacitance is set more 10 times than parasitic capacitance of the windings, and about more than $200 \mathrm{pF}$, and the corresponding winding is small than $8 \mu \mathrm{H}$.

The design and optimization target of the windings is to obtain a maximum value of quality factor $Q_{\max }$, expressed as follows,

$$
Q_{\max }=g\left(R, L_{a y}, N, h, r, s\right)
$$

And its constraints is as follows,

$$
\left\{\begin{array}{l}
R \leq R_{\max } \\
(N-1) h+2 r \leq H_{\max } \\
L_{\text {inductance }} \leq 8 u H
\end{array}\right.
$$

Radius of winding $R$ and height of winding $H$ is set to be the allowable maximum size for maximizing coupling coefficient. So, radius of the emitting winding is set to $R_{\text {emit }}=$ $R_{\text {max_emit }}=40 \mathrm{~mm}$, radius of the receiving winding is set to $R_{\text {receive }}=R_{\text {max_receive }}=25 \mathrm{~mm}$, height of winding is set to $H_{\max }=5$ $\mathrm{mm}$. And the turn numbers of the windings should be integer.

\section{1). The emitting winding}

The quality factor $Q$ vs. winding conductor radius $r$ is shown in Fig.6 under different total winding turns when setting $L_{a y}=1 \quad(H=5 \mathrm{~mm}$, winding wound with uniform $h$ in one layer). It is can be seen that, a maximum quality factor $Q$ can be obtained with $r$ variation. The maximum $Q$ will be 228 at $r=0.4 \mathrm{~mm}$ when $N=5$, and 219 at $r=0.3 \mathrm{~mm}$ when $N=6$. Therefore, a better optimized structure can be got when $N=5$.

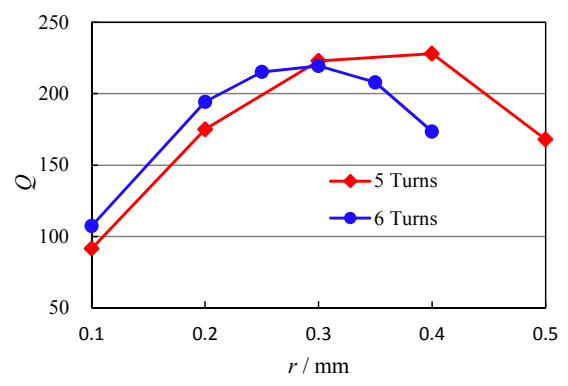

Fig.6 $Q$ vs. $r @$ single-layer winding

The quality factor $Q$ vs. $r$ and $s$ is shown in Fig.7 when setting $L_{a y}=2(H=5 \mathrm{~mm}, N=3$, winding wound with uniform $h$ on each layer). As shown in Fig.7-(a), $Q$ will be maximized at about $r=0.7 \mathrm{~mm}$; and $Q$ has the increasing trend with 
increasing $s$. Thus $Q$ vs. $s$ can be got when fixing $r=0.7 \mathrm{~mm}$, as shown in Fig.7-(b). The maximum $Q$ is 360 at about $r=0.7$ $\mathrm{mm}$ and $s=5 \mathrm{~mm}$. The $Q$ can be effectively improved with a 2-layers winding instead of 1-layer winding.

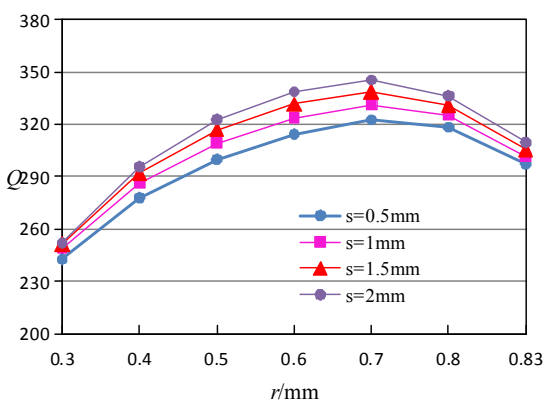

(a) $Q$ vs. r

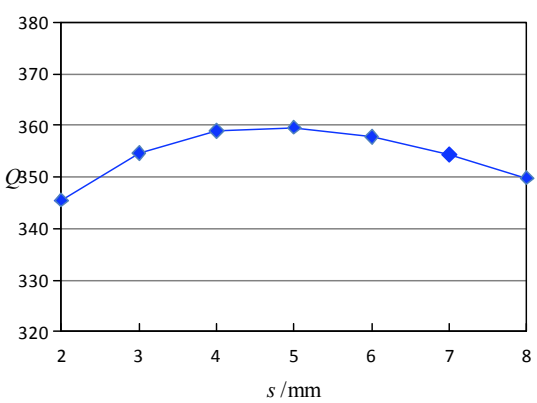

(b) $Q$ vs. $s$

Fig.7 $Q$ vs. $r$ and $s @$ two-layers winding

Similar simulations can be implemented for a three-layers winding ( $L_{a y}=3, N=3, H=5 \mathrm{~mm}$, winding wound with uniform $h$ on each layer). The result is listed in Table 2. It is shown that the maximum $Q$ is 395 when $r=0.7 \mathrm{~mm}$ and $s=4.5 \mathrm{~mm}$, and the inductance of the emitting winding is $7.3 \mu \mathrm{H}$. According to the wire gauge, the emitting winding design is as follows: $L=3, N=3, r=0.65 \mathrm{~mm}, s=4.5 \mathrm{~mm}$, winding inductance $=7.3 \mu \mathrm{H}$, compensation capacitance $=217 \mathrm{pF}$.

Table 1. $Q$ of a three-layers winding (emitting winding)

\begin{tabular}{|c|c|c|c|c|c|}
\hline & $2.5 \mathrm{~mm}$ & $3.5 \mathrm{~mm}$ & $4.5 \mathrm{~mm}$ & $5.5 \mathrm{~mm}$ & $6.5 \mathrm{~mm}$ \\
\hline $0.5 \mathrm{~mm}$ & 368 & 376 & 376 & 369 & 360 \\
\hline $0.6 \mathrm{~mm}$ & 379 & 390 & 391 & 387 & 378 \\
\hline $\mathbf{0 . 7} \mathrm{mm}$ & 383 & 393 & 395 & 390 & 383 \\
\hline $0.8 \mathrm{~mm}$ & 369 & 379 & 381 & 376 & 369 \\
\hline $0.83 \mathrm{~mm}$ & 339 & 348 & 350 & 348 & 342 \\
\hline
\end{tabular}

\section{2) The receiving winding}

The same design procedure can be implemented to the receiving winding. A three-layers winding $\left(L_{a y}=3, N=3, H=5\right.$ $\mathrm{mm}$, wound with uniform $h$ on each layer) is designed for the receiving winding. The result is listed in Table 2 . It is shown that the maximum $Q$ is 281 when $r=0.6 \mathrm{~mm}$ and $s=3 \mathrm{~mm}$, and the inductance of the receiving winding is $3.8 \mu \mathrm{H}$. According to the wire gauge, the receiving winding design is as follows: $L_{a y}=3, N=3, r=0.58 \mathrm{~mm}, s=3 \mathrm{~mm}$, winding inductance $=3.8$ $\mu \mathrm{H}$, compensation capacitance $=417 \mathrm{pF}$.
Table 2. $Q$ of a three-layers winding (receiving winding)

\begin{tabular}{|c|c|c|c|c|c|}
\hline & $1.0 \mathrm{~mm}$ & $2.0 \mathrm{~mm}$ & $3.0 \mathrm{~mm}$ & $4.0 \mathrm{~mm}$ & $5 \mathrm{~mm}$ \\
\hline $0.5 \mathrm{~mm}$ & 259 & 274 & 277 & 271 & 261 \\
\hline $0.6 \mathrm{~mm}$ & 261 & 277 & 281 & 277 & 268 \\
\hline $0.7 \mathrm{~mm}$ & 260 & 275 & 279 & 276 & 267 \\
\hline $0.8 \mathrm{~mm}$ & 252 & 264 & 267 & 263 & 255 \\
\hline $0.83 \mathrm{~mm}$ & 235 & 243 & 247 & 243 & 236 \\
\hline
\end{tabular}

\section{Experimental results}

The MR-WPS prototype is shown in Fig.8 (not including $\mathrm{PC}$ computer for receiving the monitoring data).

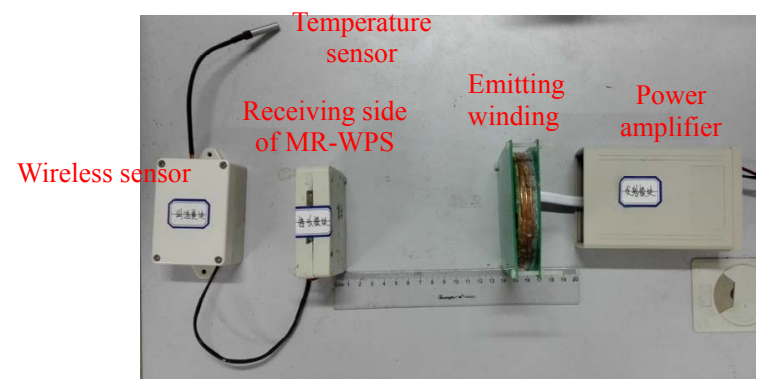

Fig.8 MR-WPS for on-line monitoring wireless sensor of HV-EE

According to operation regulations on safety, the HV-EE should be closed and locked, and no any person is permitted to access when it's operating. So key waveform and specification of the MR-WPS prototype is difficult to be tested under the operation environment of HV-EE with high-voltage and high current. Here, the experiment test scheme is with two steps to simulate the actual operation environment. The first step is to construct to simulate the environment with high-voltage (highest up to $20 \mathrm{kV}$ ) or high current (highest up to $1 \mathrm{kA}$ produced by a short bus-bar) separately. The second step is to install the MR-WPS on the HV-EE side to simulate lots of metal components environment, the same like that in Fig.10, except for the bus bar with no electricity. By the test scheme, key waveforms of the class $\mathrm{E}$ power amplifier under different transmission distances are shown in Fig.9. Where $u_{g}, u_{d}$, and $i_{o}$ represents drive signal, voltage across drain and source of MOSFET, and output current (or exciting current for the CMRU) respectively. According to the experiments, the MOSFET operates with ZVS under different transmission distances, and $i_{o}$ shows low distortion and high stable frequency. The experimental results show that operation environments with high voltage or high current and the metal components have no effects on the key waveform and specifications.

As shown in Fig.10, the prototype has been installed to run in a switchgear cabinet with rated voltage of $6.3 \mathrm{kV}$ and current $100 \mathrm{~A}$ per-phases. Installation of the prototype is shown in Fig10-(a), where a wireless sensor and its powering MR-WPS are installed on each of the three phase bus bar (only labeling one phase). Temperature of contact between the electric cable and the bus bar monitored by the wireless sensor is transmitted to PC and shown as Fig.10-(c). By the 
long-time operation from July, 2015 till now, the wireless sensors work stably, and the MR-WPS can provide enough, stable and high-reliability power for the wireless sensor.

\section{Conclusion}

A power supply of wireless sensor is one of the key components for the on-line monitoring system of high-voltage HV-EE. A MR-WPS powering for the wireless sensor installed on high-voltage side of HV-EE and the corresponding wireless sensor are proposed in this paper. Key specification of MR-WPS used in a typical HV-EE of switchgear cabinet which has harsh work environment is introduced. Model and design of the key parameters of the coupled magnetic resonant unit, and the optimizing method of the resonant windings is given. The prototype operating in 6.3 $\mathrm{kV}$ switchgear cabinet shows that the wireless sensors work stably and the MR-WPS can provide enough, stable and high-reliability power for the wireless sensor. The experiment verifies the theoretical analysis and design.

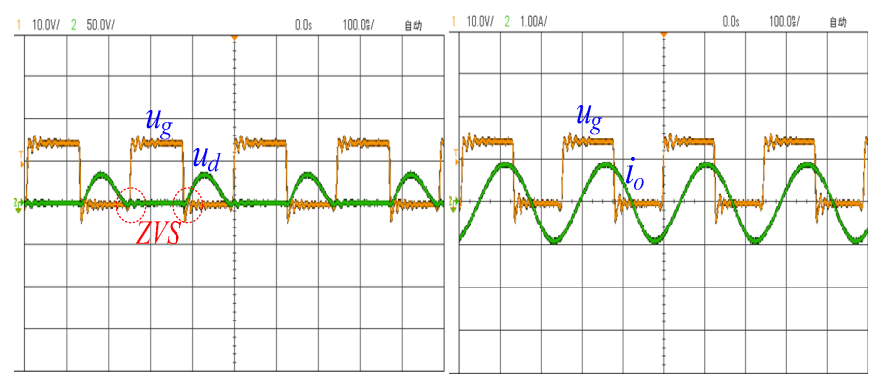

(a) Transmission distance $=13 \mathrm{~cm}$

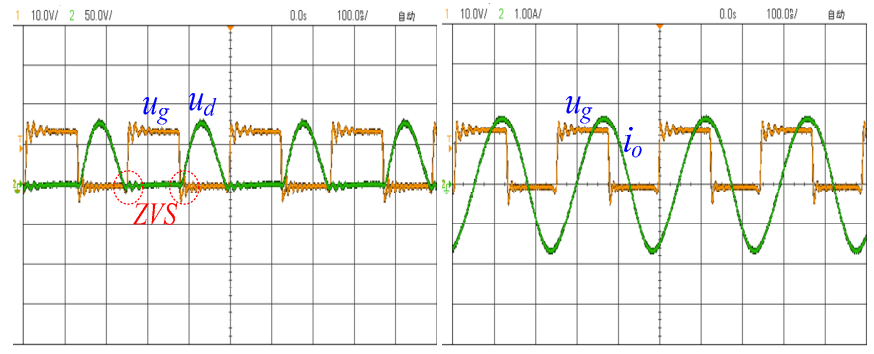

(b) Transmission distance $=18 \mathrm{~cm}$

Fig.9 Key waveforms of class E power amplifier vs. transmission distance

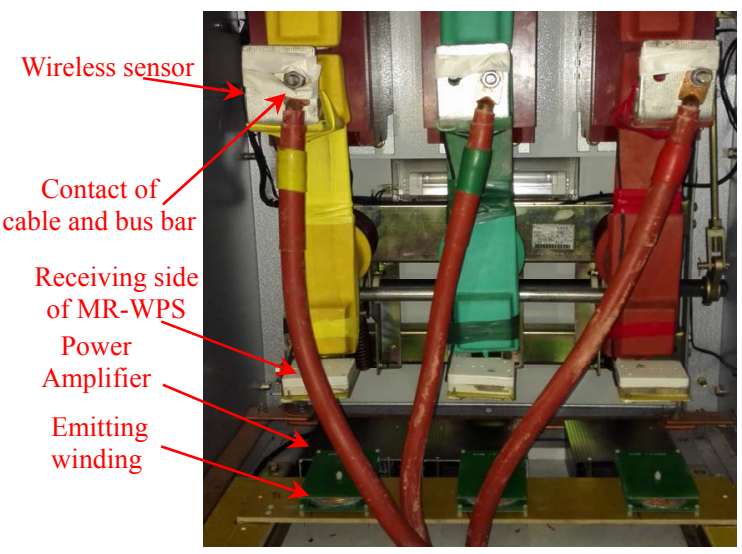

(a) The wireless sensor installation (including MR-WPS) in $6.3 \mathrm{kV}$ switchgear cabinet

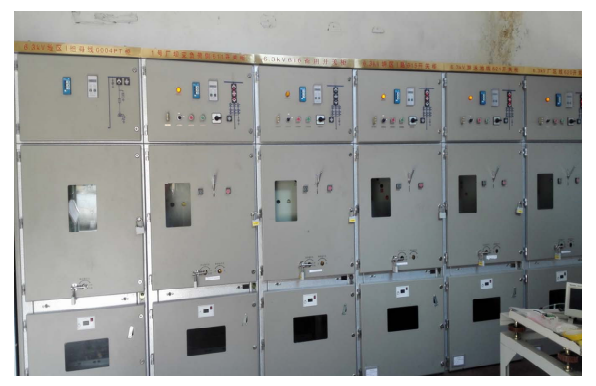

(b) $6.3 \mathrm{kV}$ switchgear cabinet

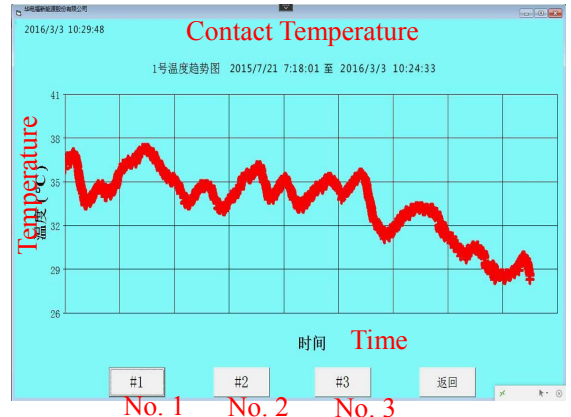

(c) Monitoring temperature displaying in personal computer

Fig.10 the wireless sensor system installation and running

\section{REFERENCES}

[1] Zangl H., Bretterklieber T., Brasseur, G., "A feasibility study on autonomous online condition monitoring of high-voltage overhead power lines", IEEE Trans. on Instrumentation and Measurement, vol.58, no.5, pp.1789-1796, 2009.

[2] Feng Guo, Hassan Hayat, Jin Wang. "Energy harvesting devices for high voltage transmission line monitoring", in Proc. IEEE Power and Energy Society General Meeting, 2011, pp.1-8.

[3] Paprotny, I., Qiliang Xu, etal , "Electromechanical energy scavenging from current-carrying conductors", IEEE Sensors, vol.13, no.1, pp.190-201, 2013.

[4] Rim, Chun T., Mi Chunting Chris, "Special Issue on Wireless Power Transfer”, IEEE Trans. on P. E., vol. 30, no. 11, pp. 6015-6016,2015.

[5] Wu H.H., et al, "A high efficiency $5 \mathrm{~kW}$ inductive charger for EVs using dual side control", IEEE Trans. on Industrial Informatics, vol. 8, no.3, pp. $585-595,2012$.

[6] A. K. Ram Rakhyani, S. Mirabbasi, C. Mu, "Design and optimization of resonance-based efficient wireless power delivery systems for biomedical implants", IEEE Trans. Biomedical Circuits and Systems, , vol. 5, no. 1, pp. 48-63, 2011.

[7] A. Kurs, et al, "Wireless energy transfer via strongly coupled magnetic resonances", Science, vol. 317, pp. 83-85, 2007.

[8] Zhao zhengming, zhang Yiming, Chen Kainan, "New progress of magnetically-coupled resonant wireless power transfer technology", .Proceedings of the CSEE. vol.33, no.3, pp. 1-13. 2013,

[9] Takehiro Imura, , and Yoichi Hori, "Maximizing air gap and efficiency of magnetic resonant coupling for wireless power transfer using equivalent circuit and Neumann formula", IEEE Trans. on Industrial Electronics, vol. 58, no.10, 2011.

[10] Wang-Sang Lee, et al, "Contactless energy transfer systems using anti-parallel resonant loops", IEEE Trans. on Industrial Electronic, vol. 60, no.1, pp. 350-359, 2013.

[11] Motoki Sato, Gaku Yamamoto, Daisuke Gunji, et al, Development of wireless in-wheel motor using magnetic resonance coupling", IEEE Trans. on P.E.vol. 31, no.7, pp. 5270-5278,2016

[12] Sharma P., Guha S. "Transmission of time varying magnetic field through body tissue", Journal of Biological Physics, vol.3, no.2, pp. 95-102, 1975. 